Revista Iberoamericana, Vol. LXXI, Núm. 213, Octubre-Diciembre 2005, 1029-1045

\author{
LA CONSTRUCCIÓN DE UN "HÉROE MÁXIMO”: \\ JOSÉ ARTIGAS EN LAS CONMEMORACIONES URUGUAYAS DE 1911 \\ POR \\ Carlos Demasi \\ Universidad de la República
}

\title{
LA IDENTIDAD ENTRE LA MEMORIA Y EL OLVIDO
}

La elaboración de la figura de los héroes nacionales es una tarea que se vincula muy estrechamente con la construcción de la identidad nacional, por lo que comparte muchas de sus características; particularmente aquella que tiende a presentarlos como "objetos" incambiados en el tiempo. Pero la identidad, como dice Gillis, forma parte de esas construcciones políticas y sociales y debe ser tratada como tal: "No podemos seguir asignándoles el estatus de objetos naturales, considerándolos como un "fenómeno” con existencia más allá del lenguaje [...] no son cosas sobre las que pensamos, sino con las que pensamos” (5, traducción mía). Por lo tanto, se trata de entidades en permanente cambio según las modificaciones de la sociedad, y en ese sentido nunca están "terminadas” en cuanto la misma sociedad que los constituye, los reelabora permanentemente modificándolos en la medida que ella misma se modifica.

Este trabajo de reelaboración no ocurre de la manera continua e imperceptible del cambio social, sino que es esporádico y tiene algunos momentos fuertes que significan puntos de inflexión: a partir de allí la comunidad consolida una nueva imagen de sí misma y, consecuentemente, instituye una nueva "figura” del héroe (ya sea por sustitución de la figura heroica, o por resignificación de la ya existente); es decir, momentos en el que la sociedad materializa su cambiante realidad y sus difusas expectativas concretándolas en la construcción de un ser ideal.

Pero si bien en términos generales estas ideas pueden ser fácilmente compartibles, resulta más complejo cuando se trata de identificar estas modificaciones en ejemplos históricos concretos, ya que estas transformaciones en modo alguno aparecen como evidentes; por el contrario, la concepción identitaria supone la permanencia en el tiempo, por lo que las modificaciones deben quedar ocultas o deben presentarse como simples perfeccionamientos de detalle de una entidad que sigue siendo la misma en lo esencial. Conviene detenerse en el análisis de este mecanismo. S. Gourgouris lo caracteriza así:

[...] puede decirse que la peculiaridad de la nación como tipo específico de sociedad reside precisamente en la operación nacionalizante en sí misma, en el proceso por el cual una sociedad instituye a sus miembros como sujetos nacionales. Esta operación, a la que Étienne Balibar ha llamado "la nacionalización de la sociedad” consiste en el modelado de una fantasía nacional históricamente específica: el eje en torno al cual se teje una 
experiencia de la nacionalidad. La vida de esta trama -que en otro idioma podría también ser llamada fácilmente fantasiebildung - se aclara mejor en referencia a los atributos peculiares del propio proceso de soñar. (82, traducción mía)

Por la peculiaridad de crear una realidad a partir de una "fantasía” compuesta de elementos simbólicos y afectivos, Gourgouris destaca las características comunes de la construcción de la nacionalidad con la experiencia de los sueños:

\begin{abstract}
Sobre este carácter afectivo del objeto y la afectación de la interpretación se basa mi afirmación sobre la esencial ininteligibilidad de la forma particular como una sociedad dada "selecciona" lo que es su modo de organización llamado nación. Para decirlo directamente: una nación no puede ser leída como un texto; incluso debemos desconfiar si parece tomar sentido. Por esto es que resulta decisivo percibir la naturaleza formal de la nación como similar a la de un sueño. Atribuir al imaginario nacional las características de una exclusiva formación discursiva no da cuenta de su complejidad. (83, traducción mía)
\end{abstract}

Por ello, las conmemoraciones (en cuanto compuestas de elementos no solamente discursivos) son en sí mismas instancias que contribuyen a la recreación de la memoria nacional, y esta reconstrucción a su vez obliga a reestructurar el proceso conmemorativo, marcando hitos importantes en aquellos momentos que por su especialidad constituyen un referente destacable. Es claro que ningún momento es destacable “a priori” y su importancia surge en el proceso de la propia elaboración; es un hecho admitido que las razones políticas son fundamentales en este caso, y que el Estado nacional juega un papel decisivo en su definición. Igualmente puede aceptarse que, siendo la nación una "identidad relacional" -es decir una "configuración histórica diseñada para incluir grupos y excluir otros”(Duara 32, traducción mía), la conmemoración nacional sería la manera de celebrar (y a la vez, instituir) una nueva configuración de la comunidad en la que han "ingresado" nuevos integrantes (y de la que, más discretamente, también se han realizado exclusiones). Conviene aclarar que esto no supone la existencia de un grupo o institución que pueda atribuirse su autoría; si bien puede rastrearse la intencionalidad de algunas propuestas, en último término es en el marco de la sociedad en su conjunto donde se le adjudica sentido, y este no dependerá solamente del proyecto que guíe al autor sino del resultado de un complejo proceso de negociación social.

Estos conceptos son particularmente útiles para analizar el caso uruguayo, porque de otra forma resultaría inexplicable la profundidad y permanencia de la institución imaginaria que comenzó a instaurarse en 1911. La nación considerada como un producto de la elaboración social supone la construcción de una identidad que englobe la enorme diversidad social; esto exige la puesta en funcionamiento de un complejo simbólico que utiliza un repertorio de variadas prácticas rituales ya frecuentes en la representación de naciones: desfiles, inauguraciones de monumentos, discursos, publicaciones históricas y literarias, eventos artísticos, instancias públicas de convocatorias dispares que se desarrollan tanto al aire libre como en locales cerrados. Dentro de éstas, generalmente se privilegia la construcción del "relato histórico" como una instancia relevante en la creación de la nación; pero éste no es ajeno a los condicionamientos que conforman a toda la instancia 
conmemorativa. ${ }^{1}$ Aunque por sus características es uno de los principales elementos de construcción de sentido, en este aspecto no es diferente de la poesía o de los discursos patrióticos: todos ellos funcionan como elementos instituyentes del tiempo y configuradores de la memoria.

El estudio de las figuras de los héroes nacionales, en cuanto compendio de "los valores y normas de comportamiento que quieren hacerse aceptar por la comunidad" (Giraldi 196, traducción mía), puede proporcionarnos una valiosa vía de acceso para estudiar la emergencia de esos elusivos momentos de transformación. En un mismo colectivo social pueden reconocerse sin dificultad diferentes versiones de la figura heroica a través del tiempo; y si bien la concepción identitaria los presenta con una imagen estática e invariable, estas transformaciones muchas veces resultan demasiado evidentes para que puedan pasar completamente ocultas. La laboriosa instauración de la figura heroica aparece en esos casos como una tersa y progresiva evolución que conduce desde el “desconocimiento” y la "incomprensión” de los contemporáneos, a través de sucesivas “revelaciones” hasta el triunfo definitivo de la "verdad histórica”. En cualquier caso, al momento de la enunciación todo el proceso ya se ha completado y el presente es percibido como el "fin de la historia”, es decir una situación en la que no cabe esperar transformaciones.

Un ejemplo de ese proceso es el caso del héroe nacional uruguayo José Artigas, una de las figuras más complejas del proceso revolucionario del Cono Sur. En febrero de 1811, con cuarenta y seis años de edad, desertó del ejército español y se incorporó a la Junta de Mayo, y luego de una conflictiva actuación pública terminó derrotado en 1820, buscando refugio en el Paraguay donde murió treinta años después. Durante su actuación pública Artigas fue el primer propagandista de las ideas federales en la región y llegó a liderar una liga de seis provincias (cinco de ellas se integraron posteriormente a la Argentina), con la que enfrentó durante cuatro años al gobierno de Buenos Aires y a una invasión militar desde la vecina colonia portuguesa del Brasil.

Los diez años de actuación de Artigas en la revolución plantearon un problema casi insoluble para la historia nacional uruguaya, que no podía eludirlo en cuanto era uno de sus antecedentes más importantes pero tampoco podía integrarlo a un relato del pasado circunscripto a los límites del territorio nacional. El proceso de la "reivindicación de Artigas” y el de la construcción de la historia nacional van estrechamente ligados y recorren las etapas de la formación de la “identidad uruguaya”, por lo que nos proporciona un conjunto de ejemplos que nos permiten estudiar las condiciones de re-creación de la figura heroica y, por extensión, proporciona pistas sobre las transformaciones de la identidad colectiva.

LAS CONMEMORACIONES DE 1911

Los festejos del Centenario de la Batalla de las Piedras (programados para el 18 de mayo de 1911) fueron la instancia en la que se procesó la exaltación de la figura de Artigas. Históricamente representan la primera “gran conmemoración” de la comunidad nacional

\footnotetext{
${ }^{1}$ Gourgouris recuerda la frase de Castoriadis: "el imaginario social no tiene historia", tanto porque hace la historia presente como porque es historia en el sentido más profundo y por tanto no puede tener a la historia como contenido (Dream 16).
} 
uruguaya, es decir, la primera vez que el colectivo social elaboraba una instancia destinada a celebrarse a sí mismo y representarse como "nación”. Sin lugar a dudas, un elemento central para la construcción del sentido era la elaboración de un relato lineal que describiera el desarrollo de la comunidad desde las guerras de la independencia hasta el presente y que justificara la instancia de la conmemoración, materializándola en un personaje que encarnara el complejo racional-emotivo de la "nación uruguaya”. Así es como la figura de Artigas aparecía naturalmente vinculada con el aniversario de la batalla que ganara a las fuerzas de Montevideo, y que representó uno de los primeros triunfos militares del movimiento iniciado en Buenos Aires casi un año antes.

Conviene señalar que el momento elegido para realizar la conmemoración tiene características especiales: no se trató de "utilizar" el aniversario para celebrar a la comunidad, sino que también instituyó un "Centenario” como instancia de celebración. Recordemos que probablemente la primera conmemoración de un "centenario” fue el de la revolución norteamericana en 1876, seguido del de la revolución francesa trece años después; el entorno de 1910 representó la oportunidad para que los países surgidos de la caída del imperio español ingresaran al "concierto internacional de naciones”. El gobierno argentino utilizó el "Centenario de Mayo" como una oportunidad para celebrar la definitiva instauración del predominio de Buenos Aires sobre el conjunto del país (Reese 22), una situación que era muy reciente en el tiempo pero que la conmemoración misma permitía instituir como "fundacional".

Esto representó un desafío para la elite dirigente uruguaya, que venía de soportar situaciones muy conflictivas: sólo seis años antes una sangrienta guerra civil había enfrentado durante casi un año a los dos partidos mayoritarios. Es difícil evaluar actualmente el peso que tuvo esa experiencia para sus protagonistas: amplios sectores de la población (y buena parte de la dirigencia política) se habían enfrentado con las armas en la mano y habían matado o visto morir a sus parientes y amigos; para entonces, el "otro" no era el "extranjero" sino el propio vecino: en esta guerra, cada uno de los bandos había solicitado (y obtenido) ayuda del exterior; ${ }^{2}$ y si bien el episodio había terminado con la derrota de los revolucionarios "blancos" luego de la muerte de su principal caudillo-y por consiguiente el partido “colorado” había conservado el poder-, durante casi toda la década siguiente nadie pudo asegurar que la revolución no se volvería a repetir.

La guerra civil podía ser interpretada como la prueba de la incapacidad de la sociedad uruguaya para mantener su estatus independiente, pero además algunos sucesos del escenario internacional rápidamente confluyeron a reforzar esa sensación: durante los años previos a los festejos de 1910, la Cancillería uruguaya estuvo enfrentada en un serio litigio con su similar argentina por la jurisdicción de las aguas del Plata: el canciller argentino Estanislao Zeballos afirmaba que el Uruguay era "un país con fronteras secas" lo que suponía que no tenía derechos de ribereño para la navegación.

Los reclamos argentinos (y los incidentes que los acompañaron) brindaron una oportunidad para que la elite dirigente recompusiera su unidad y su liderazgo social: desde

\footnotetext{
${ }^{2}$ En una fórmula que llama la atención por su precisión, en la tradición uruguaya se ha calificado a los partidos como "patrias subjetivas", un concepto que parece ratificado por esta poderosa frontera simbólica trazada entre los partidos, más fuerte que las "fronteras nacionales”.
} 
todos los sectores políticos partieron mensajes de respaldo al gobierno, una unanimidad muy sugestiva si tenemos en cuenta que se trataba del sucesor inmediato de aquel gobernante al que una parte importante de la población había intentado derrocar con las armas en la mano. En estos momentos tan críticos, el gobierno uruguayo vino a encontrar un respaldo inesperado en la Cancillería de Brasil, que competía con la Argentina por la hegemonía diplomática en el Cono Sur. La unanimidad uruguaya se vio reforzada por ese respaldo, mientras que la situación del canciller argentino se debilitaba por las críticas internas que despertaba su actitud; aunque el problema se saldó en enero de 1910 por la firma de un acuerdo argentino-uruguayo que mantenía el statu quo en el Río de la Plata, el episodio dejaría consecuencias permanentes.

Todo este conjunto de situaciones estimularon un giro importante en la imagen que el Uruguay tenía de sí mismo y de su relación con sus vecinos. Si bien históricamente los habitantes del país se habían identificado más con los argentinos y con las actitudes de su gobierno que con el Brasil, (tradicionalmente visto como el “otro” que aspiraba a absorber su territorio), estos episodios contribuyeron a deprimir la imagen del gobierno argentino (hasta poco antes tradicional amigo y amparo de los revolucionarios blancos) que ahora se había transformado en el “enemigo”, y revaloraron la importancia del Brasil (lo que tuvo consecuencias en el nomenclator montevideano: por entonces se denominó "Avenida Brasil” a una de las calles de la capital). ${ }^{3}$

La asimilación de esta experiencia supuso un esfuerzo importante de reelaboración del pasado que redefiniera al “pueblo oriental” con relación a sus vecinos, como una forma de consolidar la comunidad que se veía “amenazada” desde el exterior y de relativizar las ásperas diferencias internas (que fue uno de los principales objetivos de este impulso conmemorativo). Esto implicaba la necesidad de instituir una ruptura con el pasado inmediato que permitiera re-presentar las supuestas unanimidades fundacionales, y a la vez exaltar una figura histórica que podía invocar apoyos que saltaran sobre las divisiones internas. Esta tarea "nacionalizante” contó con los aportes de un amplio abanico de figuras representativas de los sectores sociales ${ }^{4}$ y de los partidos políticos (que ya se perfilaban como los principales canalizadores de las inquietudes de la sociedad): la comunidad y el héroe nacional que la representaba intercambiaron muchas de sus características y se instituyeron así como parte de la "realidad social” del Uruguay.

RE-PRESENTACIÓN DEL PASADO

Las instancias conmemorativas son los momentos en los que aparecen con más claridad los usos políticos de la memoria y del pasado ya que necesariamente la construcción de la comunidad implica su legitimación, y esto supone la justificación de la distribución de poder social existente en el momento de su instauración: es decir que se

\footnotetext{
${ }^{3}$ Más tarde se homenajeó también al entonces canciller Barón de Río Branco: llevan su nombre una calle céntrica y una plaza.

${ }^{4}$ Un ejemplo de la amplitud de la convocatoria se encuentra al repasar la lista de los participantes del “Ciclo de Conferencias Patrióticas” realizado en Montevideo entre abril y mayo de 1911: en la misma conferencia intervinieron conjuntamente un jefe militar (el Gral. Dr. José Luciano Martínez) y un “agitador social”, el poeta filoanarquista Angel Falco (Inspección Nacional 147).
} 
produce la “identificación y legitimación del grupo social 'llamado naturalmente’ a ejercer el poder” conjuntamente con un "proyecto de formación del ciudadano[...] apto para ser representado” (Costa y Mozejko 64).

Para un colectivo social tan conflictuado y dividido como era el uruguayo, el hecho conmemorado debía tener cualidades que permitieran su aceptación por todos. La coyuntura de 1911 era la oportunidad para consolidar un orden político particularmente inestable; pero si la elite aspiraba a instituir su control, necesariamente debía buscar un espacio de transacción con aquellos sectores políticamente “peligrosos”. La experiencia de la guerra civil había mostrado, en uno y otro bando, la capacidad de movilización y de presión de sectores importantes de las clases bajas: estos eran los que acompañaban la convocatoria de los caudillos políticos y los que formaban el principal contingente en las guerras civiles; a estos había que involucrar ya que eran los que podían afectar más gravemente la estabilidad política y social.

Estas consideraciones explican la razón por la que los grupos dirigentes aceptaron instaurar a Artigas como principal héroe nacional. El tradicional rechazo de la figura de Artigas había sido impulsado principalmente por grupos dirigentes urbanos que veían en él todo aquello que no aceptaban: el predominio rural, el caudillismo, la exaltación del militarismo, y la guerra civil. Sin embargo, a pesar del tiempo transcurrido y de la malquerencia de los dirigentes, el recuerdo de Artigas se mantenía fuertemente arraigado entre las clases bajas del medio rural (que eran la mayoría de la población hasta comienzos del siglo xx). Si se aspiraba a instituir el "pueblo oriental" como entidad ampliamente involucrante era necesario "generar adhesión, incluso apelando a estados pasionales" (Costa y Mozejko 86) y para lograr ese propósito la invocación a Artigas se presentaba como un recurso imprescindible.

La temprana (y resignada) aceptación de la inexcusable presencia de Artigas ya había sido señalada en 1884 por uno de los primeros intelectuales que reivindicara su figura, el Dr. Carlos María Ramírez. En la Introducción a su colección de artículos periodísticos de reivindicación histórica, decía:

He sufrido como el que más la influencia de la leyenda hostil a la memoria del General Artigas [pero] el estudio atento de los hechos, ya que no en todos sus detalles, al menos en sus fases principales, había disipado en mi espíritu todo el prestigio de la leyenda patricia y levantado en cambio la figura del caudillo popular. (4)

Ramírez identificaba con precisión el antagonismo social que encerraba el juicio sobre la figura de Artigas: a pesar del esfuerzo de la "leyenda patricia” por presentarlo como un delincuente, perduraba la memoria de “caudillo popular”: esa figura popular será la que se exalte en 1911, precisamente a través de la evocación de dos de sus hechos principales: el triunfo de Las Piedras y el “éxodo”. ${ }^{5}$ El carácter eminentemente popular de

\footnotetext{
${ }^{5}$ Desde 1886 se llama así en la historia uruguaya a la retirada de Artigas del territorio (como consecuencia de un acuerdo firmado en octubre de 1811 entre el gobierno de Buenos Aires y las autoridades españolas de Montevideo), retirada en la que fue acompañado por la mayoría de la población.
} 
la memoria artiguista le confirió el perfil fuertemente democrático que lo singulariza entre el conjunto de los héroes latinoamericanos.

El consenso en torno a la figura de Artigas se articula en la construcción de un "héroe” según las dimensiones clásicas de "varones estimados en el consejo y en el combate”. El Artigas “estratega militar” de la batalla de Las Piedras, el “caudillo” del éxodo que marcha seguido de todo el pueblo, el "constituyente” que en 1813 estableció las bases del federalismo en la región, todos debían combinarse sin conflictos; una tarea compleja si se tiene presente que, en el concepto dominante, el caudillo era por definición un "bárbaro” incapaz de concebir proyectos políticos. La construcción de esta figura multidimensional implicó la puesta en práctica de los diferentes mecanismos “nacionalizantes” que son el centro de la conmemoración.

\section{LA CONSTRUCCIÓN DE SENTIDO}

La iniciativa para realizar una gran conmemoración con motivo del centenario del comienzo de la lucha contra los españoles en el territorio del Uruguay, surgió en medio del conflicto por la jurisdicción del Río de la Plata. En junio de 1909 el diputado colorado Julio María Sosa presentó un proyecto donde se resaltaba la necesidad de realizar una conmemoración específicamente “uruguaya”, y proponía apresurar la construcción de un monumento a Artigas en Montevideo para que su inauguración coincidiera con el aniversario de la Batalla de Las Piedras. En la propuesta de Sosa, el monumento debía constituirse en un símbolo de la unidad del “pueblo oriental”, un verdadero altar patriótico donde “...hemos de deponer todos, prejuicios y rencores, para vivir la vida de los ejemplos de sacrificio, de firmeza y de amor al terruño que nos legó [...] el primer Jefe de los Orientales" ("Proyecto" 343).

Esta iniciativa fue rápidamente acompañada por otros destacados intelectuales: el Dr. Eduardo Acevedo, quien pocos años antes siendo rector de la Universidad había impulsado la creación de una “revista histórica”, se aplicó a la elaboración de una respuesta a los argumentos que fundamentaban los juicios adversos contra Artigas. Juan Zorrilla de San Martín, quien desde la difusión de "La Leyenda Patria” fuera consagrado (y asumiera) el rol de "poeta de la patria”, redactó un vasto relato de la actuación de Artigas, y un joven abogado colorado, el Dr. Héctor Miranda, se encargó de estudiar uno de los más importantes documentos de Artigas, las "Instrucciones del año XIII”.

Estas obras se proponen elaborar una imagen aceptable del "héroe nacional” y reconstruir un lazo vinculante entre las diversas etapas del proceso revolucionario local desde sus más lejanos orígenes en la Colonia, hasta la jura de la primera Constitución en 1830 (momento instituido como "el fin de la historia” en el imaginario de 1910). En su “Artigas. Alegato histórico”, Eduardo Acevedo declara que su proyecto no es componer "la biografía de Artigas, ni tampoco redactar la historia del decenio 1810-1820”, sino solo "formular un alegato, con la transcripción textual de todas las acusaciones y de todos los elogios de que ha sido objeto Artigas y el examen de las pruebas producidas” (I: 21), es decir elaborar una compilación documental destinada a rebatir las acusaciones contra Artigas; pero su resultado supera ampliamente ese propósito. A lo largo de su trabajo Acevedo retoma la historia del territorio desde la época colonial, dedica extensos capítulos 
a las invasiones inglesas de 1806 y 1807 (donde Artigas tuvo escasa participación) y a la Junta de Montevideo de 1808 (donde no la tuvo en absoluto), y por otro lado extiende su desarrollo hasta 1828, cuando se estableció la independencia definitiva (para entonces hacía ocho años que Artigas se encontraba exiliado en Paraguay).

Estos aspectos revelan el propósito de Acevedo de instituir una reconstrucción del relato de la historia del Río de la Plata, con Montevideo como centro y Artigas como protagonista (dos ejes que habían sido vistos como antagónicos en la revolución rioplatense). Acevedo se involucra directamente en los aspectos políticos de su propia época al construir un Artigas completamente desligado de las pasiones partidistas que atravesaron el país durante buena parte de su vida independiente. En el último párrafo de la obra, dice Acevedo:

Tal el resultado final de la contundente prueba de este “Alegato Histórico”, reveladora de una tradición de glorias con rumbo a grandes destinos, de los que todavía se encuentran alejados los orientales, apresurémonos a decirlo, por efecto de factores personales de perturbación que jamás habrían llegado a actuar si Artigas hubiera salido triunfante en su gigantesca lucha de 1811 a 1820. (III: 868, énfasis mío)

Al llegar al final de su alegato, Acevedo supone ya consolidada la imagen de un Artigas ajeno a los partidos blanco y colorado, es decir una figura que podía considerarse con la dimensión de un héroe nacional.

El proyecto "nacionalizador" de la figura de Artigas también se encuentra en los objetivos de otra de las obras publicadas en 1910, “La epopeya de Artigas” de Juan Zorrilla de San Martín. Este aprovechó el encargo de una "Memoria” para servir de guía e ilustración a aquellos artistas que deseaban presentar proyectos para el monumento a Artigas que se levantaría en Montevideo (se suponía que muchos de ellos serían extranjeros). También en este caso el resultado superó con amplitud el marco previsto originalmente: Zorrilla organizó un vasto fresco de las transformaciones políticas desde los comienzos de la colonización española hasta el comienzo de la etapa independiente, en una obra de más de mil trescientas páginas organizada en torno a "conferencias" dirigidas por el autor a sus "amigos artistas". Aunque constantemente invoca su interpretación como "la verdad histórica” e "interpretación auténtica” de la acción de Artigas, Zorrilla se aplica desembozadamente a la construcción de un héroe unificador capaz de funcionar como el mito de origen de la nación uruguaya; por eso su trabajo puede inscribirse más cómodamente en el marco de lo poético, por la gran libertad en cuanto al manejo de las fuentes. Su propósito es claramente político, como aparece explicitado en una "carta confidencial" enviada al ministro de Relaciones Exteriores y publicada posteriormente en el prólogo de la obra:

... hacer prevalecer la verdad no es otra cosa, si bien se mira, que convertirla, no tanto en simple noticia o término de conocimiento, cuanto en objeto de amor y en motor de la humana voluntad. En estos, y otros análogos razonamientos, se fundan los que sostienen que la finalidad primordial de la historia de los pueblos no es otra que la formación del patriotismo, es decir, del sentimiento racional [sic] de amor a la patria y el culto de sus héroes. [Y más adelante proclama expresamente su pragmatismo]: El supremo intérprete 
de la historia, mis amigos, es la historia misma. Mucho más que los papeles, así sean más venerables que la barba de Júpiter. (La Epopeya I: XIII; II: 524)

El Artigas de Zorrilla es, ante todo, un héroe; por lo tanto, todo su comportamiento tiene dimensión heroica y sus acciones solo toman sentido a la luz de objetivos trascendentes, que son indiscernibles para el común de sus contemporáneos. Se trata de un "mensajero" que anuncia el porvenir y como tal, pocos lo comprenden; así explica la abundancia de testimonios negativos de sus contemporáneos, a la vez que instituye a los documentos emanados del mismo Artigas como los únicos válidos para interpretar el sentido de sus acciones. Esta posición le permite justificar todas sus actitudes ya que siempre se adopta la perspectiva del enunciador (Artigas) para juzgar todos los episodios conflictivos: solamente en un caso, cuando se mencionan las ideas proteccionistas de Artigas, se habla de “...sus errores económicos”, aunque se relativiza la falta ya que se percibe en ella "la percepción instintiva de los Zollverein o asociaciones aduaneras, que ha sido la base de las unidades nacionales europeas", para terminar diciendo: "Esta visión de Artigas es hoy todavía, como sabemos, la del porvenir en el continente americano” (La Epopeya I: 601).

El "héroe" de Zorrilla se vincula con la imagen de los héroes homéricos, en cuanto seres que están a mitad de camino entre los hombres comunes y los dioses, pero la “incomprensión” de la época le da a Zorrilla la posibilidad de colocarlo en una dimensión más que sobrehumana:

Artigas es el héroe autóctono [sic], la realidad: en él no hay crepúsculo; el sol naciente le da en la cara, y dibuja con fuego sus contornos rígidos. Veréis, pues, en él, los rasgos propios del mensajero, del héroe: la soledad, la visión profética, la revelación del mensaje divino, el secreto manifiesto, que acaban todos por entender. Veréis, por consiguiente, al lado de la admiración rayana en culto, el desconocimiento, la contradicción, la persecución, el odio; la corona, por fin, que, como la de todos los héroes, será de espinas. Y la resurrección. (La Epopeya I: 7)

La acción de Artigas en la revolución se coloca en una clave similar a la del ciclo profético de Jesús: “visión profética” que llega en la “soledad”. Luego la "revelación del mensaje divino", el "secreto" mesiánico que todos “acaban por entender” y el momento del triunfo, seguido inmediatamente por la reacción de sus enemigos que terminan por derrotarlo (la “corona de espinas” está expresamente mencionada). Este esfuerzo, un tanto desmesurado, permite dar sentido a todo el ciclo de la actuación pública de Artigas: el año 1815 de predominio artiguista sobre Buenos Aires, puede asemejarse al domingo de ramos; Francisco Ramírez y Estanislao López, los "subordinados que pactaron con Buenos Aires”, serían los Judas y 1820, el viernes santo. De esta manera la derrota militar de Artigas (una de las dificultades más serias que debió enfrentar el proceso de exaltación) podía verse como la huella de un inextricable designio divino; para reforzar esa idea, "la resurrección” se anuncia en una frase sugestivamente cortada.

Si Zorrilla muestra el ejemplo más claro de manipulación emotiva, Héctor Miranda parece el extremo opuesto: su análisis de las Instrucciones del año XIII ${ }^{6}$ se mantiene dentro

\footnotetext{
${ }^{6}$ Se denomina así al documento elaborado por Artigas para orientar la actuación de los diputados orientales en la Asamblea Constituyente que se reunía en Buenos Aires en 1813.
} 
de una línea histórica y jurídica, rastreando los antecedentes de la organización constitucional en el proceso de la revolución; esta perspectiva deja casi oculta a la figura de Artigas, que adquiere relieve por oposición a las de sus contemporáneos. Desde una perspectiva más "colorada” (un partido que reunía a buena parte de la elite anticaudillista, y que se identificaba con el gobierno desde 1865), a Miranda le interesa mostrar el perfil institucionalista de Artigas y resaltar su preocupación por darle una organización republicana a los territorios del Plata: de esta manera la figura del “Jefe de los Orientales" se distanciaba la de los caudillos (calificados generalmente como "bárbaros") de las guerras civiles posteriores a la independencia, y se instalaba en un espacio propio: el de un dirigente preocupado por salvaguardar la libertad de los ciudadanos. Pero también Miranda fija las bases democráticas y populares del movimiento que Artigas lideraba:

Tal fue el carácter de la revolución oriental. Sencilla y franca, ella quiso fundar una patria nueva, independiente de los antiguos amos y depurada de todo despotismo, sobre la base del «contrato social» y de la soberanía del pueblo, consistente, como en Rousseau, en la expresión sincera de la voluntad general. (163)

El perfil "ilustrado" de Artigas es un dato decisivo para diferenciarlo de aquellos caudillos que Sarmiento tipificara como modelos de "barbarie" en lucha contra la “civilización”. Pero la exposición de las ideas del caudillo también debía servir para legitimar la situación del Estado uruguayo, con estatutos independientes como resultado de un proceso que culminó recién a fines de la década siguiente. Miranda establece un lazo directo entre esa independencia y el texto de las "Instrucciones":

Las Instrucciones del año XIII, deben ser miradas por todos los que observan a fondo los sucesos históricos, como la más formal declaración de la independencia oriental, formulada en un documento de alto significado político, de vasta resonancia y de consecuencias revolucionarias y fecundas. (245) ${ }^{7}$

Los tres autores se empeñan en construir una figura de Artigas aceptable-y aun como un modelo deseable- para la mayoría de la población. En ellos (especialmente en Zorrilla y en Miranda) está muy presente el modelo clásico vinculado al "héroe” homérico (las referencias a Homero aparecen en los dos autores); en cambio, Acevedo se apega más estrictamente a un formato judicial, que culmina con su correspondiente "alegato de bien probado”. Pero a pesar de sus matices y de algunas arriesgadas interpretaciones de los textos, se integraron al "nation dream-work" y pasaron a constituirse en obras históricas “definitivas” sobre Artigas. Sin embargo, la audacia de la construcción de Zorrilla lo hizo objeto de críticas: si bien parecía compartible la exaltación patriótica que la informaba, no todos estaban dispuestos a aceptar el fundamentalismo católico en el que inscribe el proyecto político de su personaje, ni el comportamiento monacal que le atribuye: aunque por muchas de sus facetas su Artigas reunía las condiciones de un “héroe nacional”, tales características podían alejarlo demasiado de la comunidad que trataba de representar.

\footnotetext{
${ }^{7}$ En el discurso inaugural del Congreso Artigas descartaba expresamente esa interpretación, y
} aclaraba que esto "ni por asomo se acerca a una separación nacional". 
EL PROGRAMA DE FESTEJOS

No fue posible combinar la inauguración de la estatua de Artigas con el festejo de 1911 como era la intención original, pero en cambio sí se construyó un monumento "en el campo en que se desarrolló la acción” de Las Piedras, ${ }^{8}$ el primero que se erigió en el país para conmemorar un acontecimiento de la guerra contra la dominación española. Durante los meses de abril, mayo y junio de 1911 se desarrolló un nutrido programa de festejos que incluyó actos patrióticos, ciclos de conferencias, desfiles militares y escolares, recepciones, inauguraciones, etc. Los momentos principales fueron el desfile patriótico realizado en Montevideo el domingo 21 de mayo, y la inauguración del monumento de Las Piedras, previsto originalmente para el 18 pero que, por “el mal tiempo” (y también por una huelga general), debió postergarse para el 25 de mayo.

Las crónicas de la época destacaron la importante participación popular en los festejos realizados en Montevideo, especialmente en el desfile del 21 de mayo, “[...] una verdadera apoteosis, no recordándose en el Uruguay manifestación de ningún género que adquiriese proporciones más grandiosas. La columna cívica se extendía en un espacio mayor de doce o catorce cuadras" (Inspección Nacional 125). Si bien la multitud puede parecer bastante modesta, debe tenerse presente que en la segmentada sociedad uruguaya de entonces no había ninguna convocatoria que pudiera reunir tal cantidad de asistentes.

Los festejos realizados en el campo de Las Piedras, en cambio, no contaron con el mismo marco de público, lo que algunos atribuyeron a la huelga general (la primera en la historia) que dificultó el traslado del público y empañó el brillo del desfile militar ya que el gobierno había decretado el acuartelamiento de las tropas. El acontecimiento principal debía ser la inauguración del monumento de Las Piedras, formado por una estructura de unos trece metros de altura compuesta por un obelisco de piedra coronado por la figura de una victoria alada de bronce, una forma que tenía ya su tradición conmemorativa en la región desde la erección de la "Pirámide de Mayo" en Buenos Aires (Suárez 10). Pero curiosamente, la publicación de los festejos del Centenario realizada por la Inspección Nacional de Primaria no tiene ninguna descripción del monumento ni referencia a su autor. Solamente al pie de una de las fotos (entre páginas 78 y 79) se lo describe como “...todo de piedra, y coronado por el genio de la Victoria, irguiéndose alado en su vuelo de bronce”. En un pasaje de la oratoria de Zorrilla de San Martín, este describe el monumento con lenguaje poético; pero la preocupación de Zorrilla no era la descripción de algo que todos tenían ante la vista; le interesaba más dotar de sentido a la construcción:

La Comisión del Centenario de Las Piedras, en cuyo nombre y representación os hablo, hace entrega al pueblo de este que debemos considerar como el patrio altar de los holocaustos. Como la savia del árbol, subirá por esa piedra desde las profundidades de nuestra tierra el espíritu de la Patria Oriental, y allá arriba, proyectado sobre el cielo, en la forma alada del genio criollo que corona el obelisco, será luz y será grito, será recuerdo y será esperanza; será fuerza y será altivez y será gloria. (Inspección Nacional 146)

\footnotetext{
${ }^{8}$ El diputado Sosa señalaba que la vaga indicación diputado apuntaba a "dar cierta libertad en la elección del lugar” (“Batalla...” 825).
} 
Para resaltar el brillo del acto de inauguración se había levantado en la avenida de acceso otro monumento, de carácter efímero, que representaba un arco de triunfo construido en madera y cartón. Es curioso que en la reseña oficial el arco decorativo tenga más relieve que el monumento de piedra que es el centro del espacio monumental. Tal vez la comparación que hace Marcel Suarez entre la descripción del monumento que hace Walter Laroche y la evidencia visual, proporcione una pista:

Walter Laroche revela que "la Victoria original es una figura femenina alada, descalza, con una sobretúnica que le cae del hombro. Una corona ciñe su frente. Cabello largo, facciones griegas y la mirada, gesto y posición hacia adelante y ascendente.

En la cintura y ajustando la túnica, unas boleadoras enlazadas. En el brazo y mano izquierdos, un escudo de defensa con forma redonda y una lanza hecha de una caña tacuara en cuya punta está enastada una hoja de cuchillo; en actitud pasiva, de triunfo. En la mano derecha, en alto, sostiene una rama de laurel”.

Este historiador revela parte del secreto de la imagen: la presencia de elementos indígenas. Pero una observación actual, de lo que se puede distinguir desde el suelo, puede agregar más elementos: las facciones de la figura no son realmente "griegas”, sino más bien aindiadas, ojos pequeños y rasgados, pómulos salientes, nariz casi aquilina y de caballete ancho. La "corona" bien puede ser una vincha con plumas, la corta prenda de cuero que cubre la túnica larga puede ser asociada a las prendas que usaban nuestros indios. La lanza es una chuza de la Patria Vieja y las boleadoras complementan el componente nativo de la alegoría. Incluso la rama de laurel, si se pudiera ver en detalle, podría darnos la sorpresa de ser en realidad parte de algún árbol autóctono... (12. La cita de Laroche corresponde a "Estatuaria en el Uruguay” 2, 93-94)

El esfuerzo de Laroche por incluir el monumento en la genealogía del clasicismo chocaba muy fuerte con los atributos nativos (boleadoras, lanza de tacuara) que le impuso Ferrari: una imagen tan idiosincrática contradecía la intención de los organizadores de crear un marco “clásico”. Parece inocultable el desagrado de Zorrilla frente al monumento: fue suyo el diseño del arco que adornaba la entrada a la avenida, y en su discurso no le dedicó ni una mención al escultor; incluso hay motivos para suponer que esta actitud de Zorrilla no fue pasajera: años después, cuando la misma comisión juzgue los proyectos para el monumento a Artigas, será Zorrilla el encargado de explicar la preferencia por el proyecto de Zanelli (que fuera finalmente aprobado) contra el que presentara Ferrari. ${ }^{9}$

\section{LA RECOMPOSICIÓN DEL RELATO}

Todo el esfuerzo conmemorativo debía culminar en una fórmula que recompusiera la identidad nacional reconstruyendo el relato como una continuidad. La conmemoración podía crear un sentimiento de nación y transformarlo en hechos visibles, pero una de las pruebas de su éxito ha sido la institución de la figura de Artigas como principal referente

\footnotetext{
${ }^{9}$ En esa oportunidad, Zorrilla fundamentó de esta forma el fallo en el seno de la Comisión: “el Artigas de Zanelli puede no ser un retrato de Artigas, pero es la forma bella, consagrada por la humanidad e inteligible para todos los hombres, del espíritu del héroe Oriental...” (Frega 131).
} 
de la nación: desde entonces “antiartiguista” ha sido sinónimo de “antiuruguayo”. Pero entonces, ¿cómo explicar el "antiartiguismo" de tantas figuras relevantes del pasado?, ¿cómo justificar que desde el comienzo de la vida independiente la figura de Artigas solo recogiera críticas de labios de los dirigentes más caracterizados, mientras que su defensa se verificaba por oscuros funcionarios o por figuras políticas como los presidentes Gabriel A. Pereira o Máximo Santos, considerados “nefastos” en la historia del país? En la tarea de instituir un héroe, además de vincular a la comunidad del presente con aquella de los tiempos fundacionales, también era necesario explicar el camino que había seguido la construcción de la figura de Artigas; debía elaborarse una línea discursiva fácilmente compartible que explicara el rechazo absoluto que prevalecía a comienzos de la vida independiente y fundamentara la exaltación realizada en 1911.

En esa tarea, la historia nacional uruguaya no tenía motivos para ser demasiado original, considerando el resto de las historias nacionales de la región. La forma habitual de realizar estas recomposiciones (que son bastante frecuentes en la historia latinoamericana) es la de presentar la inversión del juicio predominante como un "descubrimiento de la verdad histórica", una supuesta reconstrucción epistemológica del proceso por el que el "héroe" se vio liberado de todas las tachas que "la incomprensión de sus contemporáneos" habían arrojado sobre su figura. En algunos casos esto ha dependido fundamentalmente de la obra de una sola persona (como es el caso de la reivindicación de San Martín realizada por Bartolomé Mitre); pero en el caso de Artigas se habían sucedido varios proyectos reivindicativos diferentes a lo largo del tiempo. Por lo tanto, para construir el camino recorrido en este caso por la "verdad histórica”, era necesario afinar la construcción de una adecuada periodización. ${ }^{10}$

En el contexto de las conmemoraciones de 1911 aparecen por lo menos dos intentos de reconstrucción del proceso reivindicatorio, presentados ambos como descubrimientos progresivos de la verdad histórica: uno de ellos lo presenta Zorrilla en La epopeya... y otro es del Dr. Juan José Segundo. La reconstrucción que propone Zorrilla es importante porque incluye la confesión (en tono autoexculpatorio) de una omisión que le fuera reprochada: en su poema histórico "La Leyenda Patria” de 1879 donde cantaba el período de la lucha contra el Brasil (1825-1828), solo hizo una referencia a Artigas. En 1910 decía Zorrilla:

Este pueblo, mis amigos, ha ido penetrando en su historia, y descubriéndose a sí mismo, en sentido inverso al orden cronológico: de los Treinta y Tres a Artigas; de Artigas a la Reconquista de Buenos Aires; de la Reconquista al significado de Montevideo como metrópoli colonial. Yo mismo, con toda mi generación de la segunda mitad del pasado siglo, abrimos el alma al sentimiento patrio en aquel período que llamaremos de los Treinta y Tres e Ituzaingó. Artigas se oía, como se sienten, entre dos ráfagas de viento, las voces que este apaga........] Esa es la razón, amigos, por qué La Leyenda Patria tomó forma musical en el alma del poeta antes que la Epopeya de Artigas, solo esbozada, pero

\footnotetext{
${ }^{10}$ Según propone Duara, la periodización puede ser vista como una “estrategia retórica para conciliar las contradicciones y las represiones necesarias para la imposición de una narrativa hegemónica”. (36, traducción mía).
} 
firmemente confesada en las estrofas ingenuas de aquella. (La epopeya II: 592, énfasis de Zorrilla). ${ }^{11}$

Esta propuesta chocaba demasiado con una experiencia que todavía estaba en la memoria de todos los lectores: el "descubrimiento" de Artigas no había sido hecho de una sola vez, y el camino recorrido por la historiografía no se parecía al que presentaba Zorrilla. ${ }^{12}$ Más elaborado es el discurso de Juan José Segundo, cuando, pocos años más tarde, presentaba una conferencia de Zorrilla en el teatro Solís de Montevideo. Allí decía Segundo:

Sería curioso seguir la rehabilitación artiguista, desde la leyenda adversa hasta la gloria de hoy... Le veríamos, por ejemplo, en Carlos María Ramírez, héroe digno de laurel, pero todavía contrabandista y antipatriota en el abandono del segundo sitio de Montevideo; en Francisco Bauzá, personal e impulsivo en extremo, pero sobre todo, inferior, puesto que no supo morir...; en Lorenzo Barbagelata, limpio de toda mancha en su juventud, que era el período más tenebroso; en Eduardo Acevedo, moral e históricamente superior a todos los hombres de Mayo; en Héctor Miranda, redactor personal de las famosas Instrucciones, para llegar, por fin, a "LA EPOPEYA...” de Zorrilla de San Martín, donde el guerrero alcanza las alturas del "Héroe" de Carlyle, motor del mundo, y necesario en la historia para la revelación del secreto destino de su pueblo. (La epopeya I: XXIX)

La genealogía que traza este párrafo coincide más con la sucesión de los aportes realizados por la historiografía; pero en lo esencial describe un "camino de perfección" recorrido por la figura de Artigas en el que cada autor libera al héroe de alguna mácula que afectaba su imagen, hasta llegar al momento presente donde ya no hay nada más que agregar ni que quitar. Ciertamente que no todos los autores lograron los resultados que se les adjudican, ${ }^{13}$ pero en cambio Segundo sí logró instituir un resumen aceptado del proceso

${ }^{11} \mathrm{Al}$ respecto, el doctor Eustaquio Tomé, autor de una prolija edición crítica de “La Leyenda Patria”, anotó lo siguiente: "Zorrilla supo explotarla [a esta única referencia] cuando las investigaciones históricas impusieron, aun a los extraños, la glorificación de nuestro héroe epónimo [sic], y se hizo notar la timidez del recuerdo que, casi incidentalmente, se le consagra en La Leyenda" (La Leyenda 59).

${ }^{12}$ La "Historia de la dominación española en el Uruguay" de F. Bauzá, la obra que da sentido a Montevideo "como metrópoli colonial”, había sido publicada en 1880, es decir antes que comenzara la reivindicación artiguista; en 1906, es decir muy poco antes de las conmemoraciones del Centenario, se había realizado una opaca celebración de la participación montevideana en la reconquista de Buenos Aires que había sido ocupada en 1806 por tropas inglesas.

${ }^{13}$ En Archivo Artigas, 477-86, se incluye una serie de cinco documentos sobre las actividades de Artigas como contrabandista, que llegan hasta el año 1796. En Las Instrucciones..., H. Miranda problematiza el concepto de "autor" pero no "demuestra" que Artigas fuera el autor de las Instrucciones. Es extraña la inclusión de F. Bauzá en la lista, solo justificable por su prestigio como historiador: sus opiniones negativas sobre Artigas insinuadas en la primera edición de 1880, aparecen reafirmadas en la segunda edición de su obra, en 1895 cuando ya la reivindicación comenzaba a abrirse camino. 
de reconstrucción. Desde entonces se asume que tal ha sido la "verdad histórica” de la reivindicación artiguista.

\section{CONCLUSIONES}

A partir del caso uruguayo hemos intentado repasar las características de una etapa del proceso de construcción de un héroe nacional. El resultado puede verse como una combinación de la configuración social de la época y los antecedentes históricos, es decir una reestructuración de lo que ya estaba presente en la realidad social. Este aspecto es lo que permite reconstruir la identidad, ocultando la fractura implícita en el proyecto. Como dice Duara,

Lo que aparece como la delineación de la evolución de la nación es un complejo proceso de represiones y recreaciones, la inmersión del "otro" en el "nosotros”. Para nosotros, en nuestra posición de historiadores modernos, la aceptada transparencia de la historia lineal nos oculta sus estrategias retóricas para contener esas represiones, para prevenir una ruptura en el cuerpo de la nación. (33, traducción mía)

A pesar de todo, parece posible reconstruir las diferentes historias que se ocultan debajo del relato hegemónico y establecer un balance de los recuerdos y los olvidos negociados en el proceso, ineludibles para la construcción de un "héroe máximo" como un personaje sin sombras. Si bien puede considerarse que la historia adversa fue “superada” por el esfuerzo concentrado en torno a la conmemoración de 1911, en cambio fueron suprimidos de la memoria social tanto los perfiles autoritarios del caudillo como la identificación imaginaria de Artigas con los sectores caudillistas rurales y más especialmente con el partido blanco. Del éxito que coronó esa tarea da prueba la convicción (hoy predominante en Uruguay) de que Artigas no guarda relación con los partidos tradicionales, cuando en el siglo xIX se lo consideraba el iniciador de las luchas civiles en la región y el antecedente directo del Partido Federal argentino, aliado histórico del Partido Blanco uruguayo. ${ }^{14}$

Aparentemente, este último ha sido uno de los resultados mejor logrados: actualmente se considera que la reivindicación histórica de Artigas y su exaltación como héroe nacional está basada en su equidistancia de los dos partidos políticos tradicionales responsables de las guerras civiles que agitaron al país en el siglo xIx. El "nation dream-work” impide ver los testimonios tan explícitos como el de Carlos María Ramírez, y solamente como una curiosidad se menciona el hecho de que la mayoría de los defensores de la figura de Artigas en el siglo xix fueran figuras vinculadas al partido blanco. Pocas veces la equidistancia política de Artigas se ha visto como el resultado de una transacción entre ambos partidos; al respecto Caetano y Rilla formulan una observación muy interesante: “La búsqueda de

\footnotetext{
${ }^{14}$ Más de treinta años antes, Carlos María Ramírez repasando la relación entre Artigas y los partidos políticos, afirmaba: "Nadie ignora que el partido blanco [...] fue siempre artiguista", y a esa tradición se agregaba, tardíamente, "los honores que el general Santos tributa hoy a esa memoria, en nombre del partido colorado” (175-6, énfasis míos).
} 
un Artigas ‘fundador' de la misma, de un Artigas ‘uruguayo' que no es ni blanco ni colorado pero al que todos terminan por incorporar, será una confesión de impotencia [de los partidos] para asignarse aquel mérito en exclusividad” (11). La instauración de la figura de Artigas como héroe máximo supone la creación de una instancia superior a los partidos políticos (que aparece aludida como “la nación”, “la república”, “el país” o “el Estado”) que involucra a los uruguayos por encima de sus diferencias políticas; y en este sentido hace posible la coexistencia de parcialidades al interior de la nación. Aunque quedaba por resolver la forma cómo podía relatarse la historia del país en su etapa independiente, ya los partidos no serían “enemigos” sino "adversarios” es decir que compartirían la tarea de ejercer la hegemonía social.

\section{BibliografíA}

Acevedo, Eduardo. Artigas. Alegato histórico. Montevideo: Imp. Atenas, 1950.

Caetano, G. y J. Rilla. “El sistema de partidos: raíces y permanencias”. De la tradición a la crisis. Pasado y presente de nuestro sistema de partidos. G. Caetano y otros. Montevideo: CLAEH-EBO, 1985. 9-39.

Comisión Nacional del Archivo Artigas. Archivo Artigas. t. IV. Montevideo, 1953.

Costa, Ricardo y Danuta Teresa Mozejko. El discurso como práctica. Buenos Aires: Homo Sapiens, 2001.

Duara, Prasenjit. Rescuing History from the Nation. Questioning Narratives of the Modern China. Chicago/London: University of Chicago Press, 1995.

Frega, Ana. “La Construcción Monumental de un Héroe”. Humanas 18/1-2 (Porto Alegre, 1995): 121-49.

Gillis, John R. "Memory and Identity: the History of a Relationship". Commemorations. The Politics of National Identities. John R. Gillis, ed. New Jersey: Princeton University Press, 1994. 5-24.

Giraldi, Norah. “Artigas: mythe et symbole de la construction d’une nation”. Ateliers. Maison de la Recherche, Université Charles-de-Gaulle - Lille 3, 29/2003. 195-251.

Gourgouris, Stathis. Dream Nation. Enlightement, Colonization and the Institution of Modern Greece. Stanford: Stanford University Press,1996.

"Notes on the Nation's Dream-Work". Qui Parle 7/1 (1993): 81-101.

Inspección Nacional de Primaria. Centenario de la Batalla de Las Piedras. Montevideo, 1912.

Miranda, Héctor. Las instrucciones del año XIII .Montevideo: A. Barreiro y Ramos, 1910.

Ramírez, Carlos Ma . Artigas. Montevideo: Biblioteca Artigas, 1953.

Reese, Thomas. "Buenos Aires 1910: representación y construcción de identidad". Buenos Aires 1910: el imaginario para una gran capital. M. Gutman y Th. Reese, eds. Buenos Aires: Eudeba, 1999. 21-30.

Sosa, Julio María. “Batalla de Las Piedras (Informe a la Comisión Nacional del Centenario de la Batalla de Las Piedras)”. Revista Histórica II (1910): 825-71.

"Proyecto de actos conmemorativos del centenario de la batalla de Las Piedras". Montevideo: Diario de Sesiones de la Cámara de Representantes 199 (1909): 3414. 
Suarez, Marcel: “La batalla de Las Piedras en la construcción de la conciencia nacional”. La Gaceta. Revista 19. Asociación de Profesores de Historia del Uruguay, junio 2001. 3-15.

Zorrilla de San Martín, Juan. La Leyenda Patria. Introducción de Arturo Sergio Visca. Estudio crítico de Eustaquio Tomé. Montevideo: Biblioteca Artigas, 1979. La epopeya de Artigas. 2 ed. Barcelona, 1916. 